\title{
Corrosion Behavior of Ti and TI6AI4V in Citrate Buffers Containing Fluoride Ions
}

\author{
Anelise Marlene Schmidt ${ }^{\mathrm{a}}$, Denise Schermann Azambuja \\ ${ }^{a}$ Departament of Biology and Chemistry, University of Ijui, \\ P.O. Box 560, Ijui - RS, Brazil \\ ${ }^{\mathrm{b}}$ Laboratory of Electrochemistry, Institute of Chemistry, \\ Federal University of Rio Grande do Sul, P.O. Box 15003, Porto Alegre, RS - Brazil
}

Received: June 12, 2009; Revised: November 23, 2009

\begin{abstract}
The effect of fluoride ions concentration on the electrochemical behavior of Ti grade 2 and Ti6Al4V in citrate buffers was studied. Open circuit potential (OCP) measurements and voltammetric studies of the samples in the fluoride containing citrate buffers revealed a dissolution process when the $\mathrm{pH}$ falls below 5.0 and the $\mathrm{NaF}$ content is higher than $0.01 \mathrm{M}$. However, in citrate $\mathrm{pH} 7.6$ the materials showed a passive behavior even in $0.1 \mathrm{M}$ $\mathrm{NaF}$. Some micrographs of Ti grade 2 obtained after longer immersion times in citrate pH 5.0 with $0.01 \mathrm{M} \mathrm{NaF}$ showed a surface attack. EIS (Electrochemical Impedance Sprectroscopy) data obtained at the OCP revealed that the film resistance decreases when the immersion time is increased in $\mathrm{pH} 5.0$ containing $0.1 \mathrm{M} \mathrm{NaF}$. In the citrate $\mathrm{pH} 7.6$ the EIS data indicated a two-layer model of an oxide film consisting of a more compact inner layer and a porous outer layer. On the other hand, the EIS results in citrate $\mathrm{pH} 4.0$ change significantly when the fluoride ions concentration increases from 0.01 to $0.05 \mathrm{M}$. The electrochemical data revealed that the corrosion behavior of Ti grade 2 and Ti6Al4V in the citrate buffers depends on the $\mathrm{pH}$, the fluoride content and the exposure time.
\end{abstract}

Keywords: Ti, Ti6Al4V, citrate, fluoride

\section{Introduction}

$\mathrm{Ti}$ and its alloys are extensively used in medicine and dentistry due to their high resistance to corrosion and biocompatibility with living tissues of the human body. It is well known that Ti undergoes an osseo-integration process when it is placed in contact with bones ${ }^{1,2}$. However, the corrosion resistance of Ti decreases when fluoride ions are present in the media. Solutions containing more than $20 \mathrm{ppm}$ of fluoride ions may attack Ti surfaces when the $\mathrm{pH}$ falls below $6.0^{[3]}$.

It is well known that the corrosion and pitting processes on Ti-based alloys depend on the fluoride content and the $\mathrm{pH}$ of the media $^{4-10}$. Previous works reported that the dissolution of the oxide passive film occurs on Ti grade 2 and Ti6Al4V in fluoride containing citric acid ${ }^{4}$. According to Reclaru ${ }^{5}$, pitting was detected at some Ti alloys in saliva containing $0.1 \% \mathrm{NaF}$ and $\mathrm{pH}<4.0$. Schiff $^{6}$ showed that the corrosion resistance of Ti6Al4V alloy in artificial saliva decreased at $\mathrm{pH} 2.5$. Further, Frateur ${ }^{7}$ observed $\mathrm{TiO}_{2}$ dissolution in $0.2 \mathrm{M}$ fluoride ions concentration with $\mathrm{pH} 2.0$. According to Huang ${ }^{8}$, an increase in fluoride ion concentration leads to a decrease of the corrosion resistance of Ti6Al4V alloy in acid artificial saliva at $\mathrm{pH} 5.0$ and $37^{\circ} \mathrm{C}$. Moreover, in acidic solutions the fluoride ions form HF and a concentration over $30 \mathrm{ppm}$ results in destruction of the $\mathrm{TiO}_{2}$ passive film ${ }^{9,10}$.

$\mathrm{NaF}$ and other fluoride compounds are commonly employed in dental treatments. In fact, most-toothpastes and gels used to remove stains from enamel contain a concentration of about 1 and $2 \%$ of fluoride, respectively, with a $\mathrm{pH}$ between 3.5 and neutral. Despite the benefits of fluoride ions, their infiltration into dental implants may cause Ti corrosive attack if the $\mathrm{pH}$ is below neutral. Furthermore, citric acid and citrates are commonly employed in juices and some industrialized foods, so they can contact Ti alloy dental prosthese, which demonstrates the importance of studying the corrosive processes of these materials. The aim of this work is to investigate the corrosion behavior of Ti grade 2 and Ti6Al4V in citrate buffers containing different fluoride ion concentrations by electrochemical techniques.

\section{Experimental}

A conventional three-electrode cell was used for the electrochemical experiments, for which the working electrodes were commercialy pure Ti grade $2^{[11]}$ or Ti6Al4V ${ }^{12}$ rods (Table 1) inserted into a Teflon holder with exposed geometric areas of 0.0177 or $0.0314 \mathrm{~cm}^{2}$, respectively. The samples were acquired from Camacan ${ }^{\circledR}$ Industrial Ltda, Brazil. These electrodes were polished with 600 and 1200 emery papers, degreased with acetone and rinsed in pure water before each measurement. The reference electrode was the saturated calomel electrode (SCE), to which all the potentials were referred, and a Pt wire was used as the counter electrode.

Ti grade 2 sheets $\left(1 \mathrm{~cm}^{2}\right)$ were examined by scanning electronic microscopy (SEM) in the JSM5800 device from JEOL ${ }^{\circledR}$. The samples were polished with 600 and 1000 emery papers, degreased with acetone and rinsed in pure water before the immersion tests.

The citrate buffers were prepared with $0.1 M$ citric acid aqueous solutions ( $\mathrm{pH} 2.0$ ) and the $\mathrm{pH}$ was adjusted to 4.0 or 5.0 with $0.1 \mathrm{M}$ sodium citrate aqueous solution ( $\mathrm{pH} 7.6)$. $\mathrm{NaF}$ was added to the citrate buffer $\mathrm{pH} 4.0$ at concentrations of $0.01,0.025,0.05$ or $0.1 \mathrm{M}$ to investigate the effect of the fluoride content. All electrolytes were naturally aerated at room temperatures $\left(20 \pm 1{ }^{\circ} \mathrm{C}\right)$.

Electrochemical impedance spectra (EIS) were obtained using an Autolab PGSTAT-30 device in a frequency range from $10^{5}$ to $10^{-3} \mathrm{~Hz}$ and the amplitude of the sinusoidal signal was $10 \mathrm{mV}$. The experimental data were evaluated using a simple-least squares fitting 
Table 1. Composition/wt. (\%) of Ti and Ti6Al4V alloy (maximum values) reported by the supplier.

\begin{tabular}{lccccccc}
\hline \multicolumn{1}{c}{ Sample } & $\mathrm{N}$ & $\mathrm{C}$ & $\mathrm{H}$ & $\mathrm{Fe}$ & $\mathrm{O}$ & $\mathrm{Al}$ & $\mathrm{V}$ \\
\hline Ti grade 2 & 0.03 & 0.10 & 0.015 & 0.30 & 0.25 & - & - \\
Ti6Al4V & 0.05 & 0.10 & 0.0125 & 0.40 & 0.20 & $5.5-6.5$ & $3.5-4.5$ \\
\hline
\end{tabular}

procedure. The experimental data presented a good fitting by the transfer functions of the equivalent circuits (EC) proposed with an error of less than $10 \%$.

The voltammetric curves were obtained using the same device with a sweep rate of $0.05 \mathrm{~V} / \mathrm{s}$. The tests were carried out three times to ensure reproducibility.

\section{Results and Discussion}

Figure 1 presents the OCP of Ti6Al4V variation with the immersion time in the citrate buffers containing $0.1 \mathrm{M} \mathrm{NaF}$. The OCP in the citric acid ( $\mathrm{pH} 2.0$ ) was found to decrease to $-1.0 \mathrm{~V}$ in the first 5 minutes, indicating the primary oxide film dissolution. It is known that the reaction of $\mathrm{NaF}$ with $\mathrm{H}^{+}$produces $\mathrm{HF}$ that dissolves the oxide film on titanium surfaces ${ }^{13}$. In the citrate buffer $\mathrm{pH}$ 5.0 the OCP shifts to $-0.6 \mathrm{~V}$ and remains at this potential after an hour immersion. According to Kelsall ${ }^{13}$, at this potential and $\mathrm{pH}$ there is the formation of the lower oxide $\mathrm{Ti}_{2} \mathrm{O}_{3}$ in equilibrium with dissolved $\mathrm{Ti}$ producing $\mathrm{Ti}^{3+}$ ions even in fluoride presence. The OCP in citrate buffer $\mathrm{pH} 7.6$ shifts to $-0.5 \mathrm{~V}$ and increases with the immersion time to values related to a passive oxide film formation, probably $\mathrm{TiO}_{2}^{[13]}$. Ti grade 2 presented the same behavior (data not shown). These results indicate that the onset of the dissolution process starts at $\mathrm{pH}<5.0$ which is in good agreement with previous data reported in the literature ${ }^{5,9,10}$.

Surface analysis of Ti grade 2 by SEM showed significant surface destruction after 4 days immersion in citric acid containing $0.1 \mathrm{M}$ $\mathrm{NaF}$ (Figure 2a). The corrosion was also observed on Ti surface after 4 days immersion in citrate buffer $\mathrm{pH} 5.0$ with $0.1 \mathrm{M} \mathrm{NaF}$ (Figure 2b). However, the micrograph of Ti grade 2 in citrate buffer $\mathrm{pH} 7.6+0.1 M \mathrm{NaF}$ did not reveal any attack on the metal surface (Figure 2c). These findings indicate that the corrosion process on $\mathrm{Ti}$ in the fluoride containing citrate buffers starts at $\mathrm{pH} 5.0$ after longer immersion times. The EDS analysis found only Ti presence. According to Nakagawa ${ }^{9,10}$, there are limits of fluoride contents and $\mathrm{pH}$ values at which the corrosion behavior of Ti changes drastically.

The OCP of Ti6Al4V after an hour immersion in citrate $\mathrm{pH} 4.0$ decreases from -0.55 to $-0.83 \mathrm{~V}$ when the $\mathrm{NaF}$ concentration increases from 0.01 to $0.025 \mathrm{M}$. However, the micrograph of Ti grade 2 after 2 days immersion in $0.01 M \mathrm{NaF}$ containing citric acid shows the surface attack (Figure 3). This fact indicates the onset of the corrosion process in $0.01 M$ fluoride ions concentration after longer immersion times.

The voltammetric curve of Ti grade 2 in $0.1 M \mathrm{NaF}$ containing citric acid shows an anodic peak around $-0.8 \mathrm{~V}$ with current densities of about $6000 \mu \mathrm{A} . \mathrm{cm}^{-2}$ indicating a dissolution process followed by a passive region (Figure 4); however, anodic currents are still observed at the reverse scan and the same anodic peak appears again with current densities of about $2000 \mu \mathrm{A} . \mathrm{cm}^{-2}$. Further, current oscillations can be seen at the reverse scan. This kind of oscillations has also been reported in the literature ${ }^{6,14}$ and was attributed to the competition between film formation and dissolution. Ti6Al4V presented the same behavior, however the higher anodic currents detected at the reverse scan $\left(5000 \mu \mathrm{A} . \mathrm{cm}^{-2}\right)$ indicate an enhanced dissolution rate. These features reveal that the film is unstable and probably contains some pores and/or defects on its surface, as dissolution processes

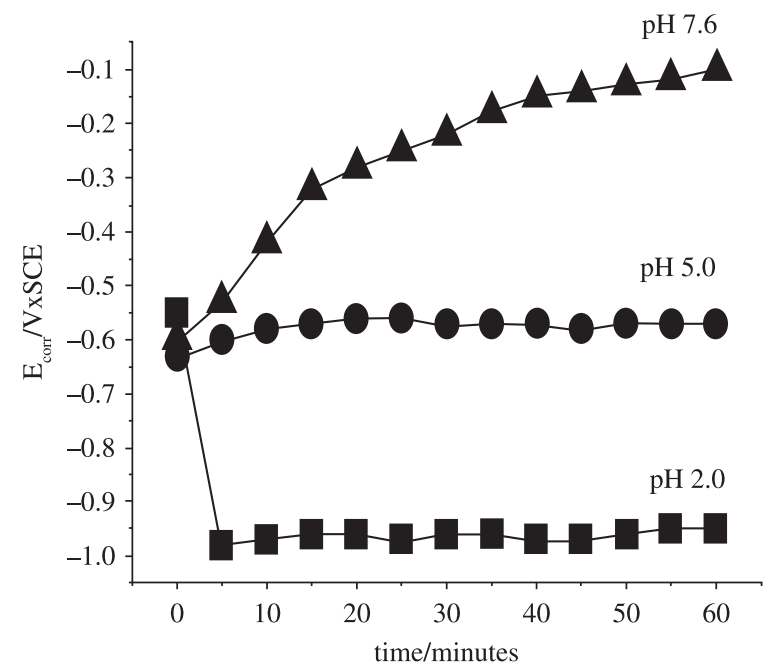

Figure 1. OCP variation of Ti6Al4V alloy as a function of immersion time in the citrate buffers containing $0.1 M \mathrm{NaF} ;(\boldsymbol{\Delta}) \mathrm{pH} 7.6,(\bullet) \mathrm{pH} 5.0,(\boldsymbol{\bullet}) \mathrm{pH} 2.0$.

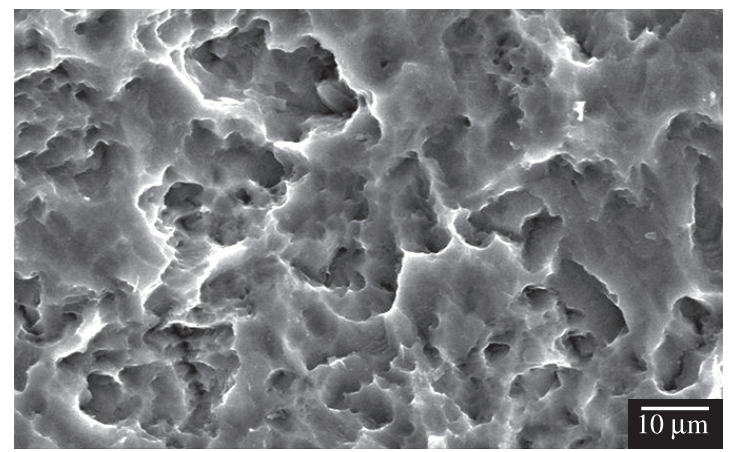

(a)

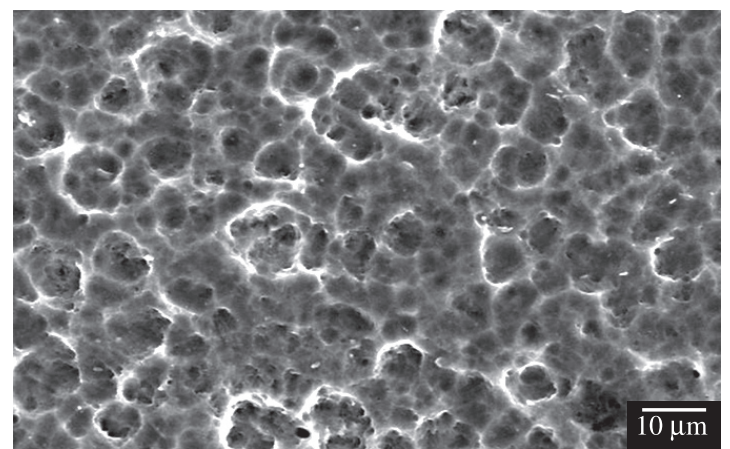

(b)

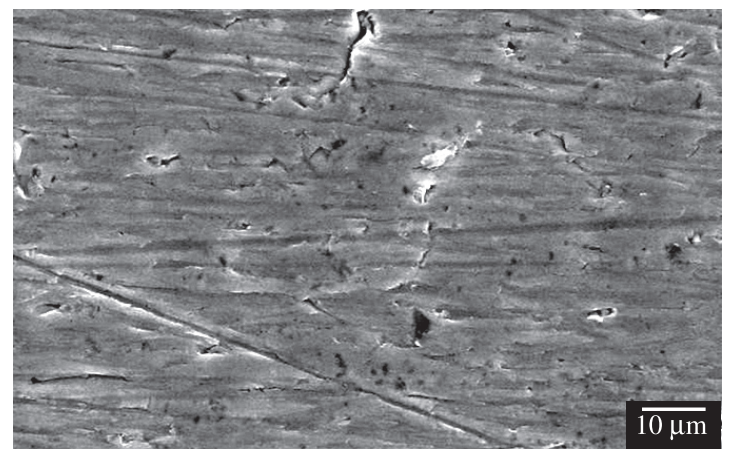

(c)

Figure 2. Micrographs of Ti obtained after 4 days immersion in the citrate buffers containing $0.1 \mathrm{M} \mathrm{NaF}$, magnification $\times 1000$; a) $\mathrm{pH} 2.0$; b) $\mathrm{pH} 5.0$; and c) $\mathrm{pH} 7.6$. 


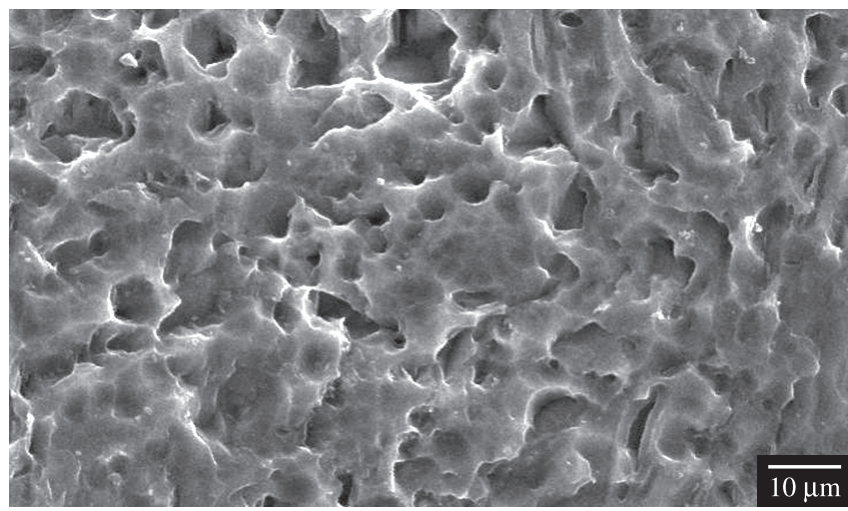

Figure 3. Micrograph of Ti after 2 days immersion in $0.01 M$ containing citric acid solution, magnification $\times 2000$.

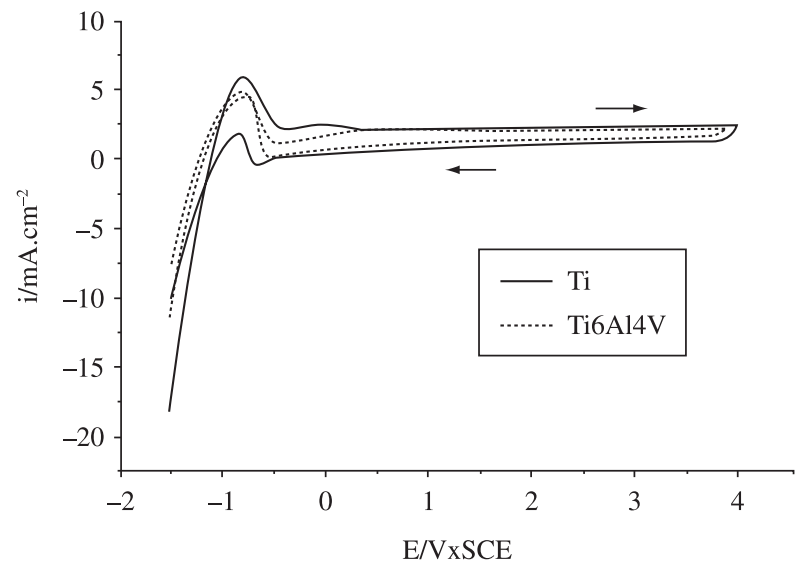

Figure 4. Voltammetric curves of Ti and Ti6Al4V in $0.1 M \mathrm{NaF}$ containing citric acid solution.

can be observed at the reverse scan. Similar results were obtained by other authors ${ }^{6,9,10}$ for Ti6Al4V in acidified salivas with $\mathrm{NaF}$ and $\mathrm{pH} \cong 4.0$, but the reverse scans were not presented. According to Shiff ${ }^{6}$, the passive region observed at anodic potentials showed that the film became stable. The major difference of our work is that the anodic currents at the reverse scan show that the film is not stable in the media evaluated.

When the $\mathrm{pH}$ of the buffer was increased to 5.0, the voltammetric curve of Ti6Al4V (Figure 5) shows an active to passive transition with current densities of about $300 \mu \mathrm{A} . \mathrm{cm}^{-2}$, in accordance with what was reported for Ti6Al4V in fluoride containing salivas with $\mathrm{pH} 5.0^{[8-10]}$. The current densities decrease to about $100 \mu \mathrm{A} . \mathrm{cm}^{-2}$ at $\mathrm{pH} 7.6$ showing a passive behavior with a current almost constant indicating the film growth, and a small cathodic peak appears around $-0.8 \mathrm{~V}$. These facts are in a good agreement with the literature indicating that $\mathrm{Ti}$ and its alloys are passive in fluoride containing media with $\mathrm{pH}>5.0^{[5,6,9]}$.

Figure 6a shows the fluoride concentration effect on the voltammetric curves of Ti grade 2 in citrate buffer at $\mathrm{pH} 4.0$. The curves revealed an active to passive behavior and the current densities increase from 250 to $600 \mu \mathrm{A} . \mathrm{cm}^{-2}$ on increasing the fluoride concentration from 0.01 to $0.05 M$. For Ti6Al4V the same behavior was observed in $0.01 M \mathrm{NaF}$, but the dissolution process is noticed at potentials close to $-1.0 \mathrm{~V}$ in the higher concentration with current densities of about $2000 \mu \mathrm{A} . \mathrm{cm}^{-2}$ (Figure 6b); however the anodic peak does not appear at the reverse scan. It is evident that Ti6Al4V is more susceptible to corrosion in this media, which is attributed to the presence of $\mathrm{Al}$

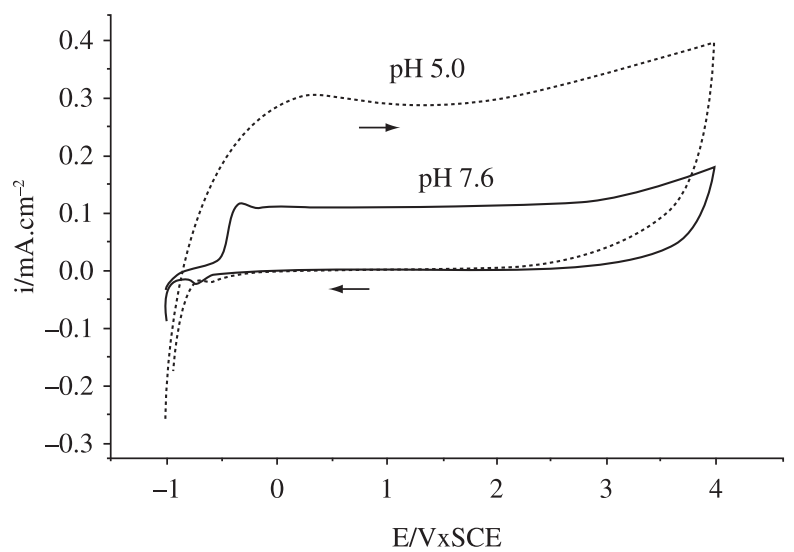

Figure 5. Voltammetric curves of Ti6 A14V in solutions at $\mathrm{pH} 5.0$ and $\mathrm{pH} 7.6$ containing $0.1 \mathrm{M} \mathrm{NaF}$.

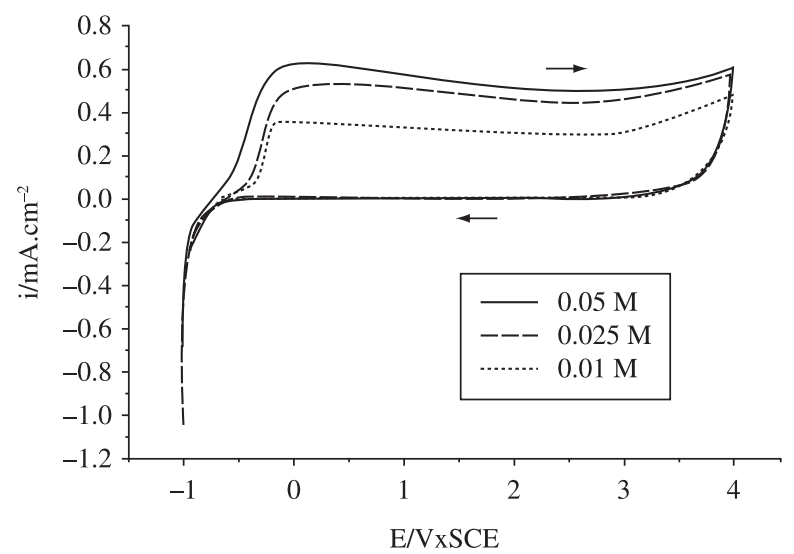

(a)

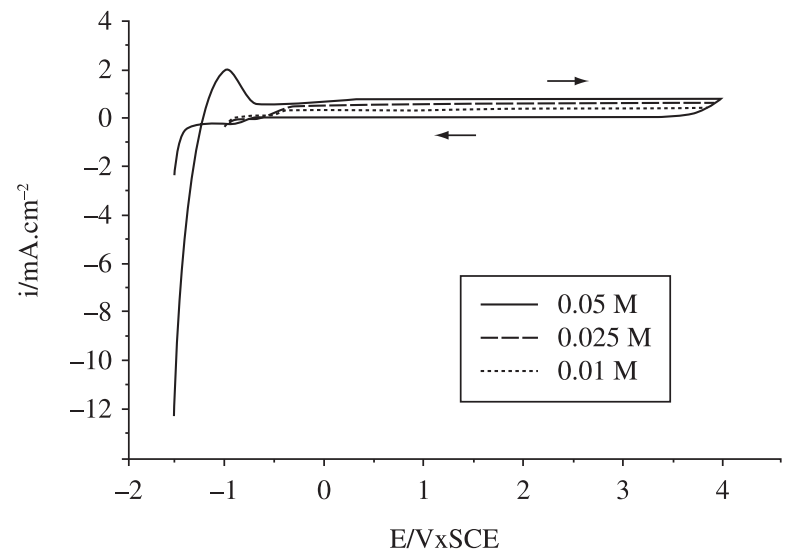

(b)

Figure 6. Voltammetric curves obtained in citrate buffer $\mathrm{pH} 4.0$ containing $0.01 \mathrm{M}, 0.025 \mathrm{M}$ and $0.05 \mathrm{M} \mathrm{NaF}$ a) Ti grade 2; b) Ti6Al4V.

and $\mathrm{V}$ causing the formation of a more defective film. In fact, $\mathrm{Al}$ and $\mathrm{V}$ improve the alloy strength ${ }^{3}$, but, on the other hand, they increase the anodic dissolution of the alloy ${ }^{15}$.

\subsection{EIS studies}

Figure 7a presents Nyquist plot of Ti6Al4V obtained after one day immersion in $0.1 \mathrm{M} \mathrm{NaF}$ containing citrate buffer at $\mathrm{pH}$ 7.6. The sepctrum shows a near capacitive behavior typical of passive materials 
and this does not change on increasing the exposure time but the film resistance decreases after 7 days immersion. These findings are different from those observed in Ringer serum containing equal fluoride concentration, in which the oxide film stability was enhanced after 7 days' immersion in this medium ${ }^{16}$. This difference may possibly be related to the presence of citric acid in the buffer producing a more defective film. These facts are in good agreement with was reported in the literature for Ti based materials ${ }^{17-22}$. The equivalent circuit (EC) used to describe the experimental data was based on a two-layer model consisting of a barrier inner layer and a porous outer layer ${ }^{16-21}$. The proposed EC is $R_{s}\left(Q_{1}\left[R_{1}\left(R_{2} Q_{2}\right)\right]\right)$ given in Figure $7 b$. $R_{s}$ is the solution resistance, $R_{1}$ and $Q_{1}$ the resistance and capacitance of the outer

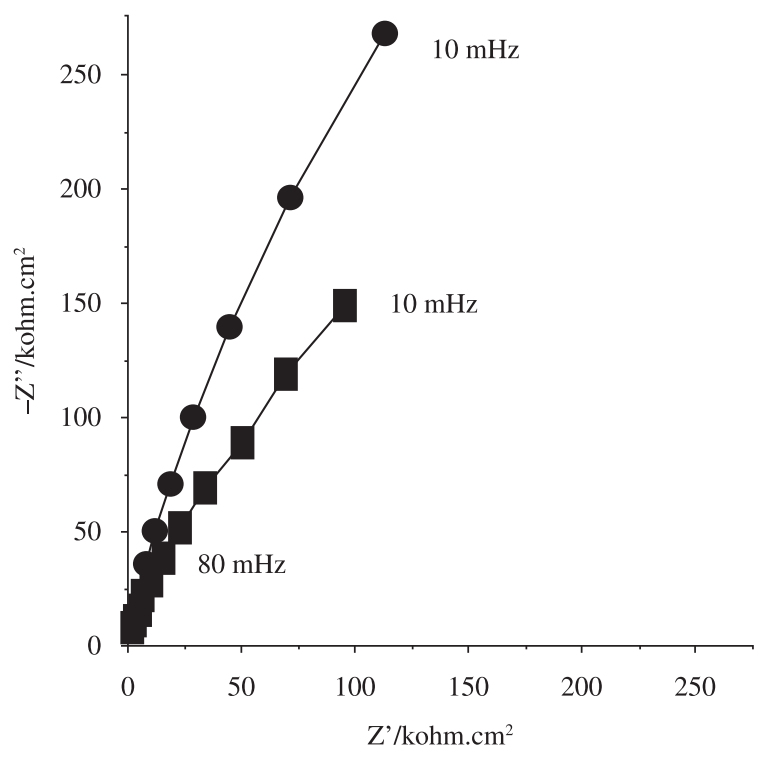

(a)

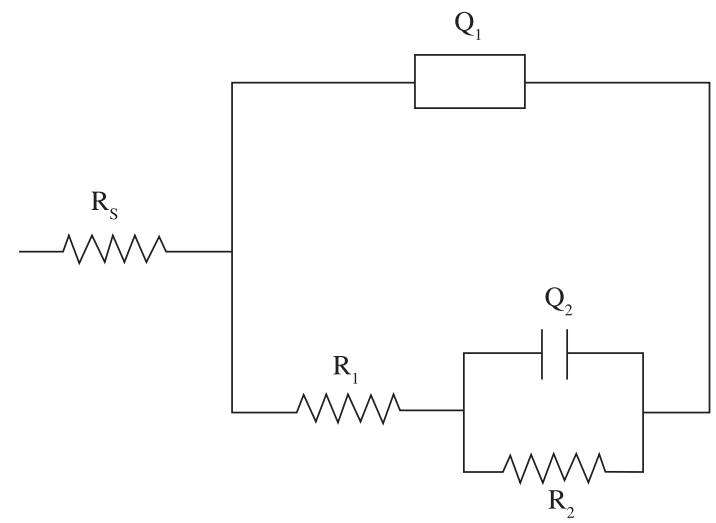

(b)

Figure 7. a) Nyquist plots of Ti6Al4V in citrate solution $\mathrm{pH} 7.6$ containing $0.1 M \mathrm{NaF}$ after 1 day $(\bullet)$ and 7 days immersion $(\boldsymbol{\bullet})$. Fitted curves in solid line. b) Equivalent circuit; $\operatorname{Rs}\left(\mathrm{Q}_{1}\left[\mathrm{R}_{1}\left(\mathrm{R}_{2} \mathrm{Q}_{2}\right)\right]\right)$ layer and $\mathrm{R}_{2}$ and $\mathrm{Q}_{2}$ the resistance and capacitance of the inner layer. According to Rammelt ${ }^{23}$ the dispersive behavior observed at rough electrodes can be described by a constant phase element (CPE). The impedance of this element is given by Equation 1:

$$
\mathrm{Z}_{\mathrm{CPE}}=\left[\mathrm{Q}(\mathrm{j} \omega)^{\mathrm{n}}\right]^{-1},-1 \leq \mathrm{n} \leq 1^{[23,24]}
$$

The value of $\mathrm{n}$ is associated with the non-uniform distribution of current as a result of roughness and surface deffects ${ }^{20}$. CPE describes an ideal capacitor for $n=1$, an ideal resistor for $n=0$ and -1 for a pure inductor ${ }^{19}$. The appearance of a CPE is due to the presence of inhomogeneities in the electrode and it can be described in terms of a distribution of relaxation times, or it may arise from non-uniform diffusion ${ }^{19}$. The simulated data are given in Table 2 .

Significant changes are observed at the Nyquist plots of Ti6A14V in the citrate buffer pH 5.0 containing $0.1 \mathrm{M} \mathrm{NaF}$ (Figure 8). The diagram obtained after 1day immersion shows a depressed capacitive response, however the emergence of a low frequency inductive looping is seen after 7 days immersion. Similar impedance spectra have been observed by Scully ${ }^{17}$ for $\beta$-Ti alloy in $5 \mathrm{M} \mathrm{HCl}$ solution. The origin of this looping is not clear but it may indicate changes in the properties of the oxide film. According to the literature this looping may be attributed to a diffusion-controled process within the oxide ${ }^{25}$ or to a surface charge at the metal-oxide interface ${ }^{26}$. The equivalent circuit proposed to describe the EIS data after 1 day immersion is the same of Figure $7 b$. For longer exposure the EC used is $R_{S}\left(C_{1}\left[R_{1} L_{1}\right]\right)$, where $R_{S}, C_{1}, R_{1}$ and $L_{1}$ represent the resistance of the solution, the total system capacitance, the polarization resistance $\left(\mathrm{R}_{\mathrm{P}}\right)$ and the inductive element, respectively (Figure 9). The results indicate that

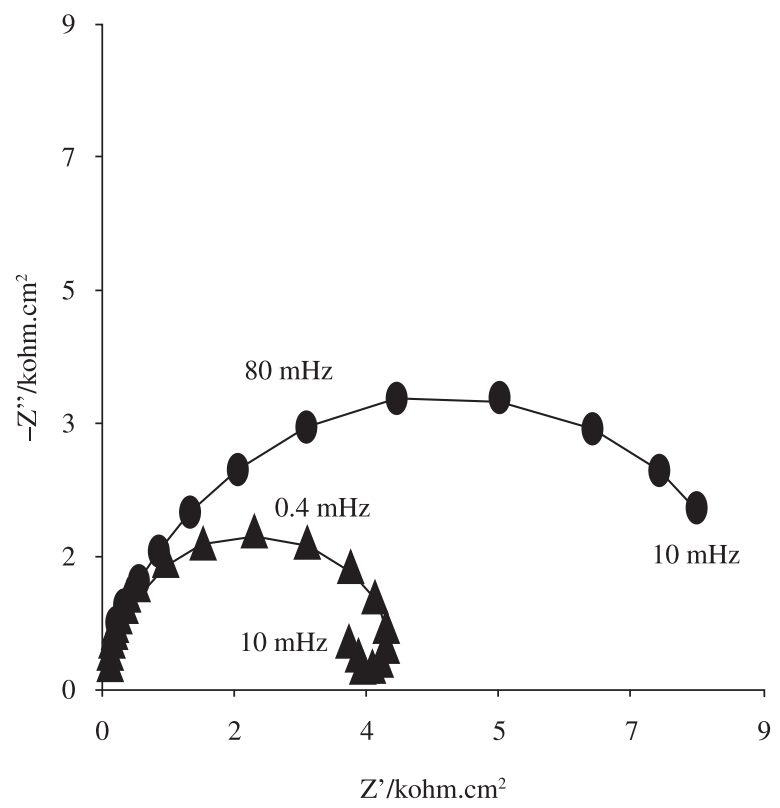

Figure 8. Nyquist plots of Ti6Al4V obtained after 1 day (•) and 7 days ( $(\boldsymbol{\Delta})$ immersion in citrate solution $\mathrm{pH} 5.0$ containing $0.1 \mathrm{M}$ NaF. Fitted curves in solid line.

Table 2. Fitting parameters used to simulate the EIS of Ti6Al4V in citrate buffer at pH7.6

\begin{tabular}{|c|c|c|c|c|c|c|c|c|}
\hline Time & $\begin{array}{l}\mathrm{E}_{\text {corr }} \\
(\mathrm{V})\end{array}$ & $\begin{array}{c}\mathrm{R}_{\mathrm{s}} \\
\left(\Omega \mathrm{cm}^{2}\right)\end{array}$ & $\begin{array}{c}\mathrm{R}_{1} \\
\left(\mathrm{k} \Omega \mathrm{cm}^{2}\right)\end{array}$ & $\begin{array}{c}\mathrm{Q}_{1} \\
\left(\Omega^{-1} \mathrm{~cm}^{-2} \mathrm{~s}^{\mathrm{n}}\right)\end{array}$ & $\mathrm{n}$ & $\begin{array}{c}\mathrm{R}_{2} \\
\left(\mathrm{k} \Omega \mathrm{cm}^{2}\right)\end{array}$ & $\begin{array}{c}\mathrm{Q}_{2} \\
\left(\Omega^{-1} \mathrm{~cm}^{-2} \mathrm{~s}^{\mathrm{n}}\right) \\
\end{array}$ & $\mathrm{n}$ \\
\hline 1 day & -0.42 & 3.7 & 236.9 & 15.3 & 0.92 & 753.5 & 13.8 & 0.96 \\
\hline 7 days & -0.30 & 3.4 & 88.1 & 15.1 & 0.92 & 315.8 & 41.7 & 0.97 \\
\hline
\end{tabular}




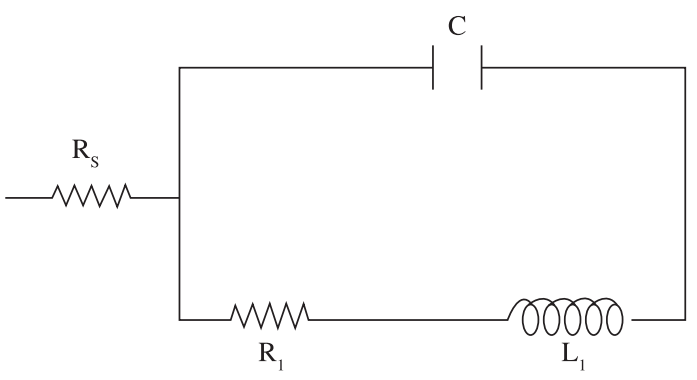

Figure 9. Equivalent circuit obtained of fitting the EIS data of Figure 8 (7 days); $\operatorname{Rs}\left(\mathrm{C}_{1}\left[\mathrm{R}_{1} \mathrm{~L}_{1}\right]\right)$.

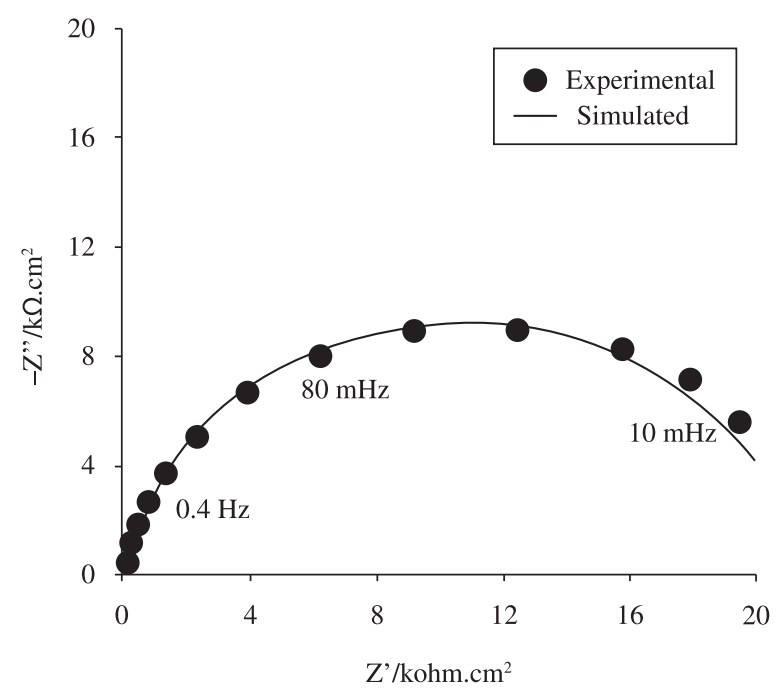

(a)

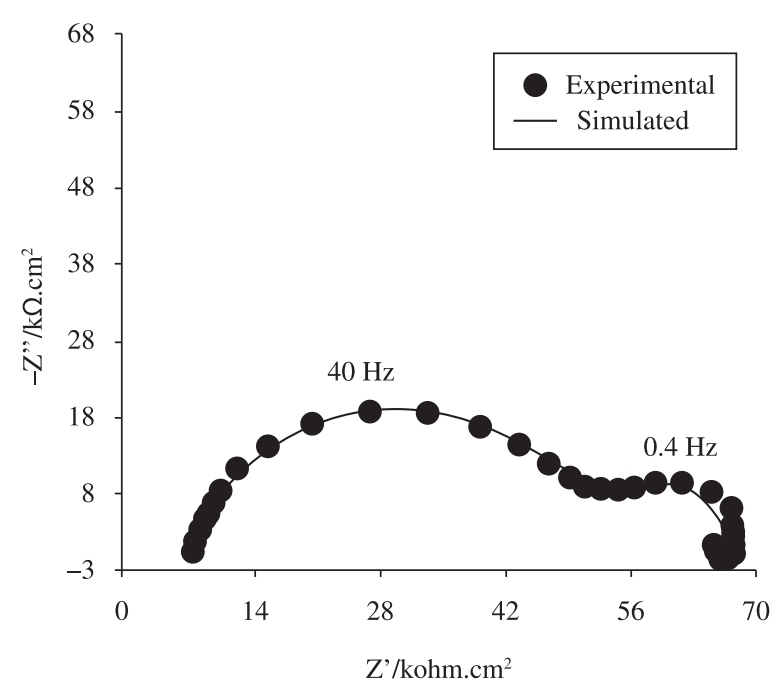

(b)

Figure 10. Nyquist plots of Ti6Al4V in citrate buffer at $\mathrm{pH} 4.0$; a) $0.01 M$ $\mathrm{NaF}$; b) $0.1 M \mathrm{NaF}$.

a dissolution process of the oxide film occurs after longer exposure in the citrate at $\mathrm{pH} 5.0$.

The Nyquist plots of Ti6Al4V (Figure 10) give the effect of fluoride ions concentration in citrate buffer at $\mathrm{pH}$ 4.0. On increasing the fluoride concentration significant changes are observed on the EIS

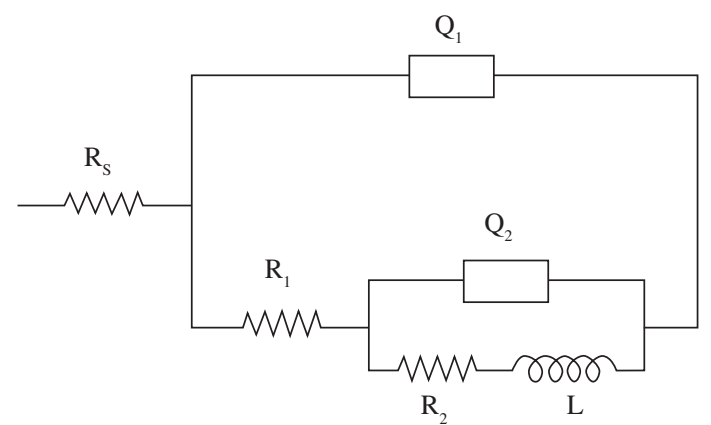

Figure 11. Equivalent circuit obtained of fitting the EIS data of Figure 10b; $\operatorname{Rs}\left(Q_{1}\left[R_{1}\left(Q_{2}\left[R_{3} L\right]\right)\right]\right)$.

spectra. The EC used to describe the EIS spectrum in $0.01 M \mathrm{NaF}$ (Figure 10a) is the same of that of Figure 7b. On increasing the NaF concentration to $0.1 M$ (Figure 10b) the diagram shows two capacitive time constants at high and middle frequencies followed by an inductive loop at the lower frequency range. This inductive time constant has often been attributed to surface or bulk relaxation of species on the oxide layer and related to active dissolution ${ }^{25,26}$. The experimental data were described by the EC (Figure 11) $R_{S}\left(Q_{1}\left[R_{1}\left(Q_{2}\left[R_{2} L\right]\right)\right]\right.$ ), where $R_{S}$, represent the resistance of the solution; $Q_{1}$ and $R_{1}$ the capacitance and resistance of the high frequencies; $Q_{2}$ and $R_{2}$ the capacitance and resistance of the lower frequencies and $\mathrm{L}$ the inductive elment. The polarization resistance $R_{P}$ is the sum of $R_{1}$ and $R_{2}$.

\section{Conclusions}

OCP measurements and voltammetric studies revealed that Ti and Ti6A14V undergo a corrosion process when the $\mathrm{pH}$ falls below 5.0 and the fluoride concentration is higher than $0.01 \mathrm{M}$. Both materials were passive in citrate buffer $\mathrm{pH} 7.6$, even in the presence of $0.1 \mathrm{M} \mathrm{NaF}$; however, in the buffer at $\mathrm{pH} 5.0$ and in $0.01 \mathrm{M} \mathrm{NaF}$ containing buffer $\mathrm{pH} 4.0$ a corrosive attack was observed at the micrographs obtained after longer immersion times.

The EIS studies confirm the passive behavior of Ti6Al4V in citrate buffer at $\mathrm{pH} 7.6$ such as the corrosive process in citrate buffers at $\mathrm{pH} 4.0$ and 5.0. Further, metal dissolution enhances on increasing the fluoride content in citrate buffer at $\mathrm{pH}$ 4.0.

The results reported here demonstrate that the corrosion behavior of $\mathrm{Ti}$ and Ti6Al4V depends on the fluoride concentration, the $\mathrm{pH}$ of the citrate buffers and the immersion time.

\section{Acknowledgements}

Financial support of this work by Brazilian agencies: CNPq, CAPES and FAPERGS, are gratefully acknowledged.

\section{References}

1. Marc L and Rack HJ. Titanium alloys in total joint replacement - a materials science perspective. Biomaterials. 1998; 19(18):1621-1639.

2. Popa MV, Demetrescu I, Vasilescu E, Drob P, Lopez AS, Mirza-Rosca J et al. Corrosion susceptibility of implant materials Ti5Al4V and Ti6A14Fe in artificial extra-celular fluids. Electrochimica Acta. 2004; 49(13):2113-2121.

3. Schutz RW and Thomas DE. Corrosion of titanium and its alloys. In: ASM International. Metals Handbook. $19^{\text {th }}$ ed. Ohio, USA: ASM International; 1987. v. 13. p. 669-706.

4. Schmidt AM and Azambuja DS. Electrochemical behavior of Ti and Ti6Al4V in aqueous solutions of citric acid containing halides. Materials Research. 2006; 9 (4):387-392.

5. Reclaru L and Meyer JM. Effects of fluorides on Titanium and other dental alloys in dentistry. Biomaterials. 1998; 19(1-3):85-92. 
6. Schiff N, Grosgogeat B, Lissac M and Dalard F. Influence of fluoride content and $\mathrm{pH}$ on the corrosion resistance of titanium and its alloys. Biomaterials. 2002; 23(4):1995-2002.

7. Frateur I, Cattarin S, Musiani M and Tribollet B. Electrodissolution of $\mathrm{Ti}$ and $\mathrm{p}-\mathrm{Si}$ in acidic fluoride media: formation ratio of oxide layers from EIS. Journal of Electroanalytical Chemistry. 2000; 482(2):202-210.

8. Huang HH. Effect of fluoride and albumin concentration on the corrosion behavior of Ti-6Al-4V. Biomaterials. 2003; 24(2):275-282.

9. Nakagawa M, Matsuya S, Shiraishi T and Ohta M. Effect of fluoride concentration and $\mathrm{pH}$ on corrosion behavior of titanium for dental use. Journal of Dental Research. 1999; 78(9):1568-1572.

10. Nakagawa M, Matono Y, Matsuya S, Udoh K and Ishikawa K. The effect of $\mathrm{Pt}$ and Pd alloying additions on the corrosion behavior of titanium in fluoride containing environments. Biomaterials. 2005; 26(15):2239-2246.

11. ASTM. ASTM F67-95. Standard Specification for Unalloyed Titanium for Surgical Implant Applications. USA: American Society for Testing and Materials; 1995.

12. ASTM. ASTM F136-98. Standard Specification for Wrought Titanium6Aluminum-4Vanadium Extra Low Interstitial Alloy for Surgical Implant Applications. USA: American Society for Testing and Materials; 1998.

13. Kelsall GH and Robbins DJ. Thermodynamics of Ti- $\mathrm{H}_{2} \mathrm{O}-\mathrm{F}$ systems at 298 K. Journal of Electroanalytical Chemistry. 1990; 283(1-2):135-157.

14. Ibris $\mathrm{N}$ and Mirza-Rosca J. EIS study of Ti and its alloys in biological media. Journal of Electroanalytical Chemistry. 2002; 526(1-2):53-62.

15. Tomashov ND, Chernova GP, Yu RS and Ayuyan GA. The passivation of alloys on titanium bases. Electrochimica Acta. 1974; 19(4):159-172.

16. Schmidt AM and Azambuja DS. Effect of fluoride ions on Ti6Al4V alloy passivation in lactated Ringer's serum. Materials Research. 2003; 6(2):227-231
17. Kolman DG and Scully JR. Electrochemistry and passivity of a Ti-15Mo-3Nb$3 \mathrm{Al}$ beta-titanium alloy in ambient temperature aqueous chloride solution. Journal of the Electrochemical Society. 1993; 140(10):2771-2779.

18. Kolman DG and Scully JR. Electrochemistry and passivity of Ti-15V3Cr-3Al-3Sn beta-titanium alloy in ambient temperature aqueous chloride solutions. Journal of the Electrochemical Society. 1994; 141(10):2633-2641

19. Shukla AK and Balasubramaniam R. Effect of surface treatment on electrochemical behavior of $\mathrm{CP} \mathrm{Ti}$, Ti-6Al-4V and Ti-13Nb-13Zr alloys in simulated human body fluid. Corrosion Science. 2005; 48(7):1697-1720.

20. Assis SL, Wolynec S and Costa I. Corrosion characterization of titanium alloys by electrochemical techniques. Electrochimica Acta. 2006; 51(8-9):1815-1819.

21. Pan J, Thierry D and Leygraf C. Electrochemical impedance spectroscopy study of the passive film on titanium for implant application. Electrochimica Acta. 1996; 41(7-8):1143-1153.

22. Gonzalez JEG and Mirza-Rosca JC. Study of the corrosion behavior of titanium and some of its alloys for biomedical and dental implant applications. Journal of Electroanalytical Chemistry. 1999; 471(2):109-115.

23. Ramhelt $U$ and Reinhard G. On the applicability of a constant phase element (CPE) to the estimation of roughness of solid metal electrodes. Electrochimica Acta. 1990; 35(6):1045-1049.

24. Bessone J, Mayer C and Juttner K. AC impedance measurements of aluminum barrier type oxide films. Electrochimica Acta. 1983; 28(2):171-175.

25. Bessone J, Salinas DR, Mayer CE, Ebert M and Lorenz WJ. An EIS study of aluminum barrier type oxide films formed on different media. Electrochimica Acta. 1992; 37(12):2283-2290.

26. Wit $\mathrm{HJ}$, Wijenberg $\mathrm{C}$ and Crevecoeur $\mathrm{C}$. Impedance measurements during anodization of aluminum. Journal of the Electrochemical Society. 1979; 126(2):779-785 